\title{
Erratum to: A characterization of the generalized functions via the special Hermite expansions
}

\author{
Toshinao Kagawa ${ }^{1} \cdot$ Yasuyuki Oka $^{2}$
}

Published online: 22 October 2015

(C) Springer Basel 2015

\section{Erratum to: J. Pseudo-Differ. Oper. Appl. DOI 10.1007/s11868-015-0133-9}

In the original publication, the name of the second author has been published incorrectly. The correct name should be "Yasuyuki Oka".

The original article has been updated accordingly.

The online version of the original article can be found under doi:10.1007/s11868-015-0133-9.

$凶$ Toshinao Kagawa

kagawa_toshinao@ma.noda.tus.ac.jp

Yasuyuki Oka

oka@kushiro-ct.ac.jp

1 Tokyo City University, Tokyo, Japan

2 General Education, National Institute of Technology, Kushiro College, 2-32-1 Otanoshike-Nishi, Kushiro-Shi, Hokkaido 084-0916, Japan 